\title{
Tryptophan Hydroxylase-I Gene Variants Associate with a Group of Suicidal Borderline Women
}

\author{
Ghazal Zaboli*,I,2, Rinat Gizatullin',2, Åsa Nilsonne', Alexander Wilczek³ , Erik G Jönsson', Ewa Ahnemark', \\ Marie Åsberg' and Rosario Leopardi ${ }^{1,2}$ \\ 'Psychiatry Section, Department of Clinical Neuroscience, Karolinska Institute and Hospital, Stockholm, Sweden; ${ }^{2}$ Center for Molecular Medicine, \\ CMM L8:0 I, Karolinska Institute, Stockholm, Sweden; ${ }^{3}$ Psychotherapy Section, Department of Clinical Neuroscience, Karolinska Institute and \\ Hospital, Stockholm, Sweden
}

\begin{abstract}
Alterations in the serotonin (5-HT) system have been related to impulsive aggression and suicidal behavior, common features of the borderline personality disorder (BPD). Tryptophan hydroxylase (TPH) is the rate-limiting enzyme in 5-HT biosynthesis. Two isoforms are known, TPH-I and TPH-2. TPH-I has been correlated to various psychiatric and behavioral disorders by gene polymorphism association studies. We aimed to determine whether specific TPH-I haplotypes associate with BPD. A case-control design was employed. The control group included 98 women without psychiatric history. In all, 95 patients were included, all Caucasian women with a BPD diagnosis who had attempted suicide at least twice during their lifetime. Exclusion criteria were: (i) substance dependence; (ii) dementia or other irreversible organic brain syndromes; (iii) psychotic disorders or major depressive illness with melancholic features; (iv) lifethreatening eating disorders. Six single-nucleotide polymorphisms (SNPs) were found at significant linkage disequilibrium across $23 \mathrm{~kb}$ of the TPH-I gene in both patients and controls, suggesting a haplotype block structure. While no individual SNP showed association, several haplotypes associated with the BPD group. In particular, one six-SNP haplotype was absent from the control group while representing about one-quarter of all haplotypes in the BPD group (corrected $P \ll 10^{-5}$ ). A 'sliding window' analysis attributed the strongest disease association to haplotype configurations located between the gene promoter and intron 3. We conclude that TPH-I associates with BPD in suicidal women. Our data support the expectation that haplotype analysis is superior to single locus analysis in gene-disease, case-control association studies.

Neuropsychopharmacology (2006) 31, 1982-1990. doi:I0.1038/sj.npp. I 301046; published online 22 February 2006
\end{abstract}

Keywords: borderline personality disorder; gene variant; haplotype; linkage disequilibrium; SNP; suicide; tryptophan hydroxylase

\section{INTRODUCTION}

Borderline personality disorder (BPD) is a serious mental condition affecting $1-2 \%$ of the general population (Swartz et al, 1990). BPD psychopathology is related to contributing elements such as interpersonal stress, affective instability, impulsivity, dissociation, and self-injurious behavior (Spitzer et al, 1992). Such elements are proposed to play a key role in the development of the disorder, and may be expressed to various degrees in different patients with BPD (Lieb et al, 2004). The disease often disrupts family and work life, long-term planning, and the individual's sense of identity.

\footnotetext{
*Correspondence: G Zaboli, Department of Clinical Neuroscience, Karolinska Institute, Karolinska Hospital, CMM L8:01, 17176 Stockholm, Sweden, Tel: + 46 (8) 51774 602, Fax: + 46 (8) 51776 180, E-mail: ghazal.zaboli@ki.se

Received 29 July 2005; revised 16 November 2005; accepted 18 January 2006

Online publication: 18 January 2006 at http://www.acnp.org/citations/ Npp0 I | 806050482/default.pdf
}

Several epidemiological studies indicate a predominance of BPD in women (about 70 vs 30\% men) (Swartz et al, 1990). BPD is associated with a history of physical or sexual trauma during childhood, which is reported by $40-70 \%$ of in-patients. The severity of borderline psychopathology has also been linked to severity of childhood sexual abuse (Silk et al, 1995; Zanarini et al, 2002). Behaviorally, BPD patients show a high rate of self-injury without suicide intent, as well as a high rate of suicide attempts and completed suicide in severe cases (Soloff et al, 1994). About $40-80 \%$ of patients with BPD report a history of major depression, and often meet Diagnostic and Statistical Manual (DSM) criteria for other psychiatric disorders such as substance abuse, posttraumatic stress disorder (PTSD), anxiety disorders, and eating disorders (Lieb et al, 2004).

Several environmental and genetic factors are considered predisposing elements (Siever et al, 2002; Skodol et al, 2002; Lieb et al, 2004). Environmental factors such as sexual abuse or situations of abandonment are proposed to induce dysfunctional behaviors and psychosocial conflicts, which in turn might cause emotional dysregulation and 
impulsivity (Lieb et al, 2004). A genetic predisposition to impulsivity and harm avoidance might contribute to an individual's vulnerability to the disorder (Siever et al, 2002). The role of a predisposing genetic background has been investigated in twin studies (Skodol et al, 2002). Torgersen $(1984,1987)$ and Torgersen et al (2000) have presented several twin studies over the years. Earlier studies from this group on a small sample of twins indicated that environment is important for development of BPD, while genetics is not (Torgersen, 1984). In another, more recent and larger study concordance rates of $35 \%$ in monozygotic (MZ) and $7 \%$ in dizygotic (DZ) twin pairs were observed, suggesting a strong genetic effect in the development of the disorder (Torgersen et al, 2000). However, more studies are required to estimate the contribution of genetic and environmental elements.

Impulsive aggression and affective instability are key domains among the contributing elements of BPD (Skodol et $a l, 2002$ ). Affective instability has been associated with increased responsiveness of the cholinergic system, while impulsive aggression correlates inversely with serotonergic activity in the brain (Skodol et al, 2002). Serotonin (5-HT) neurotransmission is related to anxiety in animal models as well as in human (Cloninger, 1987; Griebel, 1995). 5-HT turn-over is particularly active in cortical and limbic areas involved in emotional aspects of behavior (WhitakerAzmitia et al, 1990; Westenberg, 1996). There is extensive evidence for the presence of 5-HT nerve terminals and/or 5 -HT receptors in neuroendocrine regions such as hippocampus, hypothalamus, and brainstem (Chaouloff, 1993). Clinically, reduced 5-HT uptake has been associated with depression and anxiety (Iny et al, 1994; Owens and Nemeroff, 1994). The notion that the 5-HT system plays an important role in impulsive behavioral patterns is based on various studies. Structural and functional neuroimaging data show dysfunctional areas in brain networks, such as the anterior cingulated cortex (ACC), the hippocampus, and the amygdala, which are also involved in dysfunctional 5HT neurotransmission (Soloff et al, 2003). Other evidence stems from studies regarding impulsive aggression, violent behaviors, and various suicidal behaviors in correlation with 5-HT metabolites such as 5-hydroxyindole acetic acid (5-HIAA) (Cochran et al, 1976; Linnoila et al, 1983; Brown et al, 1989). Decreased levels of 5-HIAA have been observed in self-directed aggression such as violent suicidal behavior (Asberg et al, 1976), and also in externally directed aggression (Linnoila et al, 1983; Brown et al, 1989). Postmortem studies of suicidal victims have also revealed reduced level of brain 5-HT (Cochran et al, 1976; Korpi et al, 1986). Although the 5-HT system has been implicated in the etiology of impulsive aggression, the exact nature of the dysfunction remains unsolved.

Impulsive aggression is a liability component in the heritability of suicide and suicidal behavior (Brent and Mann, 2005). Twin studies have shown an increased suicide risk among co-twins even after controlling for other risk factors (Statham et al, 1998; Fu et al, 2002). In a large Australian twin study, genetic factors accounted for $45 \%$ of the variance in suicide thoughts and behavior (Statham et al, 1998). Several twin and adoption studies indicate that suicidal behavior is heritable, and heritability includes both suicide attempts and suicide completion (Brent and Mann,
2005). Both completed suicide and suicidal behavior have been reported to have higher concordance rates in $\mathrm{MZ}$ than in DZ twins (14.9 vs $0.7 \%$ and 23 vs $0.7 \%$, respectively) (Roy and Segal, 2001). Some overlap between heritability of suicidal ideation and actual suicidal behavior has been noted in twin studies ( $\mathrm{Fu}$ et al, 2002).

One of the 5-HT system genes that have been studied in relationship to aggression, anger, impulsivity, and suicidal behavior is tryptophan hydroxylase $(T P H)$ (Abbar et al, 1992; Mann et al, 1997; Nielsen et al, 1998; Kunugi et al, 1999). Since TPH is the rate-limiting enzyme in the biosynthesis of 5-HT (Cooper and Melcer, 1961), TPH variants might be expected to be related to pathogenesis events involving dysfunction of the 5-HT system. As such, $T P H$ is potentially one of the major candidate genes for genetic predisposition to $\mathrm{BPD}$, particularly in patients with suicidal behavior (Roy et al, 1997). Until recently, only one gene encoding TPH was known, which we refer to as TPH-1. The gene is located in the human chromosome 11p15.3$\mathrm{p} 14$, is about $29 \mathrm{~kb}$ long, and includes 11 exons (Craig et al, 1991). Recently, a second TPH isoform has been reported, thereby called TPH-2 (Walther and Bader, 2003). Its gene is located on chromosome 12 and shows $71 \%$ homology to TPH-1 on the amino-acid level (Walther and Bader, 2003). $T P H-1$ and $T P H-2$ are expressed in nearly equal amounts in several human brain regions such as frontal cortex, thalamus, hippocampus, hypothalamus, and amygdala. $\mathrm{TPH}-2$ is predominantly expressed in the brain stem whereas it is absent from peripheral tissues such as heart, lung, kidney, duodenum, and adrenal gland, where only TPH-1 is expressed (Zill et al, 2004a). The two most widely investigated single nucleotide polymorphisms (SNPs) in TPH-1 are A218C (rs1800532) and A779C (rs1799913) (Tsai et al, 1999). Significant associations have been reported between SNP A779C and cerebrospinal fluid (CSF) 5-HIAA concentrations among Finnish impulsive offenders (Nielsen et al, 1994). The polymorphism was also associated with violent offenders who had a history of suicide attempts (Nielsen et al, 1997). Furthermore, associations were observed in a group of depressed alcoholics (Mann et al, 1997). However, while allele 799C was associated with the mentioned Finnish patients, in the latter study allele 799A was more represented in depressed suicide attempters (Mann et al, 1997; Nielsen et al, 1998). In an extensive study, seven $T P H-1$ polymorphisms were investigated in relationship to suicidal behavior. The strongest associations were found for violent suicidal attempters with no history of depression (Abbar et al, 2001).

While the studies cited above are likely to point all to the same direction, results are conflicting, as it is often the case for single marker analyses in case-control studies, which seem prone to inconsistency in common disease association studies (Cardon and Bell, 2001; Lohmueller et al, 2003). This is generally attributed to the fact that common psychiatric disorders are expected to associate with common alleles. Thus, the use of haplotypes as more specific risk markers than single alleles is currently being explored (Judson et al, 2000; Clark, 2004). Alleles are mostly organized in haplotype blocks, that is, limited arrays of allelic combinations inherited with minimal recombination, and rather stably maintained in populations (Gabriel et al, 2002). However, reliable construction of such blocks may require 
parent-offspring transmission data, which are often not available. An alternative concept directed toward molecular pathogenic studies is the gene-based haplotype, that is, a combination of alleles located within a gene unit, independently of genetic heritability (Hoehe, 2003). Gene-based haplotypes do not necessarily correspond to haplotype blocks, as individual haplotype blocks may contain more than one gene, and one gene unit may span over several haplotype blocks. Potentially, detailed gene-based haplotypes could be the most precise markers possible for a given gene, as they would contain all the variations in the gene (Hoehe, 2003).

We have initiated studies aimed to apply the use of genebased haplotypes as a starting point for the identification of risk haplotypes within a classical case-control study design. We recently found six SNPs within TPH-1, spanning over $23 \mathrm{~kb}$ of the total $29 \mathrm{~kb}$, all at significant linkage disequilibrium (LD) with each other in a group of healthy individuals (Gizatullin et al, 2005). The SNPs are likely to belong to the same haplotype block. Here, we report a risk haplotype analysis based on these SNPs, carried out on a group of female BPD patients.

\section{MATERIALS AND METHODS}

\section{Human Subjects}

This study was approved by the Ethics Committee of the Karolinska Hospital. All subjects were unrelated Caucasian women living in the Stockholm County. Cases and controls genotyped in this study were matched for gender, ethnicity, and geographical distribution. Subjects were interviewed using the Structured Clinical Interview for DSM-III-R (Spitzer et al, 1990) or DSM-IV (Spitzer et al, 1992). The control group included 98 female individuals (mean age \pm standard deviation: $44.0 \pm 13.8$ years) recruited as reported earlier (Gustavsson et al, 1999). Briefly, subjects were either re-examined healthy individuals, mainly staff and medical students, or subjects drawn from the general population for previous biological psychiatric studies performed at the Karolinska Institute. At the time of blood collection and diagnostic interview, none of the individuals in this group had any psychiatric history. For the recruitment of the $\mathrm{BPD}$ group, information regarding a dialectic behavioral therapy (DBT) project was distributed to all Stockholm County Council psychiatric clinics, serving a population of approximately 1.8 million inhabitants. These clinics referred 162 patients, all women, with a DSMIV BPD diagnosis. One inclusion criterion for recruitment of patients in this study was at least two potentially lifethreatening suicide attempts, with at least one attempt made less than 6 months prior to referral. Lethal intent was defined according to the patient's belief that the attempt could have been lethal. Exclusion criteria were: (i) a current diagnosis of substance dependence; (ii) evidence of dementia or other irreversible organic brain syndrome; (iii) a current diagnosis of a psychotic disorder or major depressive illness with melancholic features; (iv) a lifethreatening eating disorder. A total of 95 patients (mean age \pm standard deviation: $30.5 \pm 8.1$ years) were included in the present study.
The latest suicide attempt before study inclusion was carried out with the following methods: drug overdose (70.5\%), penetrating lesions $(21 \%)$, hanging or strangulation $(6.3 \%)$, jumping $(1.1 \%)$, poisoning (1.1\%). Most patients also met DSM-IV criteria for a diagnosis of major depression or anxiety disorders. Specifically, 68 patients (72\%) had a diagnosis of major depression, 62 (65\%) a diagnosis of an anxiety disorder, and 37 (39\%) had both diagnoses.

\section{Genotyping}

Venous blood was drawn and immediately frozen in aliquots at $-70^{\circ} \mathrm{C}$ or below until analyzed. Genomic DNA was prepared from whole blood by using QIAamp ${ }^{\circledR}$ DNA Blood Mini kit (Qiagen, CA, USA). The extracted DNA was stored at $4{ }^{\circ} \mathrm{C}$ until analyzed. DNA (50 ng/reaction) was amplified by polymerase chain reaction (PCR), carried out in a T3 Thermocycler (Biometra ${ }^{\circledR} \mathrm{GmbH}$ ) in a total volume of $25 \mu \mathrm{l}$. The reaction buffer was composed of $1.5-2.5 \mathrm{mM}$ $\mathrm{MgCl}_{2}, 67 \mathrm{mM}$ Tris- $\mathrm{HCl} \mathrm{pH} \mathrm{9.2,} 16.6 \mathrm{mM}\left(\mathrm{NH}_{4}\right)_{2} \mathrm{SO}_{4}, 0.1 \%$ $\mathrm{v} / \mathrm{v}$ Tween $20,200 \mu \mathrm{M}$ dNTPs, $20 \mathrm{pmol}$ of each primers (MWG Biotech AG), and $0.75 \mathrm{U}$ of Taq DNA polymerase (Roche Diagnostic GmbH). The PCR products were then digested overnight with appropriate restriction enzymes (see Table 1), subjected to electrophoresis on $2 \%$ agarose gels (Roche Diagnostic $\mathrm{GmbH}$ ), and visualized after an ethidium bromide staining. Table 1 shows primer sequences, PCR annealing temperatures, and restriction enzymes used for each SNP.

SNP rs1799913 was analyzed by pyrosequencing, using a Pyrosequencer PSQ 96 and a PSQ 96 SNP Reagent Kit (Pyrosequencer, Uppsala, Sweden) according to the manufacturer's instructions. PCR reactions were carried out in $50 \mu \mathrm{l}$ volume containing $100 \mathrm{ng}$ genomic DNA, PCR buffer (1.5 mM MgCl $2,10 \mathrm{mM}$ Tris- $\mathrm{HCl} \mathrm{pH} 8.3,50 \mathrm{mM} \mathrm{KCl}, 0.1 \%$ $\mathrm{v} / \mathrm{v}$ Tween 20), $200 \mu \mathrm{M}$ dNTPs, $10 \mathrm{pmol}$ of each primers (the reverse primer was biotinylated), and $1.5 \mathrm{U}$ of Taq DNA polymerase (Roche Diagnostic $\mathrm{GmbH}$ ). Thermal cycling was performed with an initial denaturation for $5 \mathrm{~min}$ at $96^{\circ} \mathrm{C}$, followed by 50 cycles of denaturation for $30 \mathrm{~s}$ at $96^{\circ} \mathrm{C}$, primer annealing for $30 \mathrm{~s}$ at $55^{\circ} \mathrm{C}$, and synthesis for $30 \mathrm{~s}$ at $72^{\circ} \mathrm{C}$. A final primer extension was conducted for $5 \mathrm{~min}$ at $72^{\circ} \mathrm{C}$. The PCR products ( $140 \mathrm{bp}$ ) were run on $2 \%$ agarose gels (Roche Diagnostic $\mathrm{GmbH}$ ), and visualized after an ethidium bromide staining. A total $45 \mu \mathrm{l}$ of PCR product were used for pyrosequencing, and $15 \mathrm{pmol}$ of the forward sequencing primer were applied to detect the polymorphisms.

\section{Statistical Analyses}

Genotype and allele frequencies, as well as Hardy-Weinberg equilibrium were calculated using Microsoft Excel macro PHARE version 2.1 (developed by David Cox), which can be downloaded at http://bioinformatics.org/macroshack/ programs/PHARE/description.html.

For association analyses of individual genotypes and alleles, $\chi^{2}$ analysis on $2 \times 2$ or $2 \times 3$ contingency tables was carried out (http://www.georgetown.edu/faculty/ballc/ webtools/web_chi.html). The significance level for all statistical tests was 0.05 . 
Table I Primers for PCR Amplification and Pyrosequencing

\begin{tabular}{|c|c|c|c|c|c|c|}
\hline Marker & SNP ID ${ }^{a}$ & SNP position ${ }^{b}$ & Primer sequence & Annealing temperature & Restriction enzyme & Primer position $^{b}$ \\
\hline \multirow[t]{2}{*}{ । } & rs4537731 & 124889 & TTAATGGCATTGAAGTAAGAGCAC & $55^{\circ} \mathrm{C}$ & SaullIA & $125089-125066$ \\
\hline & & & TITGGCTCCTGGCACTTAAC & & & $124772-124792$ \\
\hline \multirow[t]{2}{*}{2} & rs684302 & 116360 & AGAGAGATGGAGCAAAACACTAC & $55^{\circ} \mathrm{C}$ & Alul & | | 6248-| | 6270 \\
\hline & & & CCAGTCCTTCCAAATCTGATAC & & & | $16459-116438$ \\
\hline 3 & rs21।105 & 111308 & CAAGGCAAGATITATATGAGTT & $55^{\circ} \mathrm{C}$ & $C f r l$ & | | | 050-| | | 07| \\
\hline \multirow[t]{2}{*}{4} & rs| 800532 & 103821 & AATGGCATCTACCTTATGGGTTC & $58^{\circ} \mathrm{C}$ & Nhel & |03993-10397| \\
\hline & & & CTITATITTCTCCATGGGACTCA & & & $103655-103678$ \\
\hline \multirow[t]{3}{*}{5} & rs|7999|3 & 103260 & ATTGGATTTCGATTTGATTG & $55^{\circ} \mathrm{C}$ & Pyr. ${ }^{c}$ & $103335-103316$ \\
\hline & & & GGCAAAACTAGGTTCAGC & & & $103196-103213$ \\
\hline & & & CAGCGTGACAAACTTGTACC & & & $103283-103264$ \\
\hline
\end{tabular}

${ }^{a}$ SNP ID number from the NCBI SNP database (http://www.ncbi.nlm.nih.gov/SNP/).

${ }^{\text {b}} \mathrm{SNP}$ and primer positions are shown based on NCBI clone ACI24058.

${ }^{\mathrm{C}}$ For detection of SNP rs 17999/3, pyrosequencing was used.

Table 2 Allele Distribution in the Study Population

\begin{tabular}{|c|c|c|c|c|}
\hline \multirow[b]{2}{*}{ SNP ${ }^{a}$} & \multirow[b]{2}{*}{ Polymorphism ${ }^{\text {b }}$} & \multicolumn{3}{|c|}{ Allelic frequencies } \\
\hline & & $\begin{array}{l}\text { Control } \\
(n=98)\end{array}$ & $\begin{array}{c}\text { BPD } \\
(n=95)\end{array}$ & $P$-value ${ }^{c}$ \\
\hline । & $A / G$ & $0.48 / 0.52$ & $0.45 / 0.55$ & 0.462 \\
\hline 2 & $\mathrm{C} / \mathrm{T}$ & $0.52 / 0.48$ & $0.63 / 0.37$ & 0.035 \\
\hline 3 & $\mathrm{G} / \mathrm{T}$ & $0.21 / 0.79$ & $0.27 / 0.73$ & 0.172 \\
\hline 4 & C/A & $0.55 / 0.45$ & $0.61 / 0.39$ & 0.164 \\
\hline 5 & C/A & $0.56 / 0.44$ & $0.64 / 0.36$ & 0.053 \\
\hline 6 & G/A & $0.46 / 0.54$ & $0.60 / 0.40$ & 0.137 \\
\hline
\end{tabular}

Bold numerals highlight significant SNPs (determined by a significant $P$-value).

${ }^{a}$ SNP numbering as in Table I.

${ }^{\mathrm{b}}$ Allele I/allele2.

${ }^{c}$ Not corrected for multiple testing.

For pair wise LD and haplotype analyses, the Arlequin program version 2.0 was used (http://lgb.unigene.ch/ arlequin). A total of 100000 permutations were performed in each analysis. Lewontin's $D^{\prime}$-values were used to illustrate the extent of $\mathrm{LD}$, and the corresponding $P$-values are also shown. Bonferroni correction was used for multiple testing.

\section{RESULTS}

\section{Single Locus Analysis}

Subjects were genotyped for the SNPs indicated as \#1-6 in Table 1. All SNPs were at Hardy-Weinberg equilibrium in both patient and control groups. Results of single locus association analyses are summarized in Tables 2 and 3. No genotype association was found with the disease. Allele association tests for BPD vs controls showed significance for SNP $2 \mathrm{C}$ allele with $\mathrm{BPD}(P=0.035$; Table 2$)$. However, this association did not maintain statistical significance after Bonferroni correction.

\section{LD Analysis}

LD data indicated as Lewontin's $D^{\prime}$-values and corresponding $P$-values were calculated for all SNP pairs in control and BPD groups as shown in Tables 4 and 5. A comparison of BPD patients to controls shows that both groups shared an almost homogeneous LD pattern with the exception of SNP 1 in the control group. This SNP was found to be in strong LD only with SNP 3. As for the other SNPs in this group, all show significant $\mathrm{LD}$ with $P$-values $<10^{-5}$. All SNPs were in high LD with each other in the patient group, with $P$-values $<10^{-5}$.

\section{Six-Marker Haplotype Analysis}

Our ultimate goal is to characterize the entire sequence of risk gene variants. To this end, haplotype-based gene variants serve as a basis to a complete sequence characterization. Six-marker haplotype analyses were carried out across the $T P H-1$ gene for the entire study population. Table 6 shows the estimated haplotype frequencies with Bonferroni corrected $P$-values. About $80 \%$ of the healthy group carried six common haplotypes (\#1-6 in Table 6), all with frequencies above $7 \%$. Significant differences were observed between groups.

Haplotypes 3 (GTTAAA) and 5 (GCTCCG) were significantly associated with $\mathrm{BPD}$, each having a frequency almost three-fold higher in BPD patients than in healthy subjects $\left(\chi^{2}=22.5, \mathrm{df}=1\right.$, corrected $P<10^{-5}$, and $\chi^{2}=10.1$, $\mathrm{df}=1$, corrected $P=0.0084$, respectively). Haplotypes 1,2 , and 4 showed an opposite pattern, as they were associated with the healthy control group (Table 6). Haplotype 1 (ATTAAA) was carried by $26.6 \%$ of the controls $v s 5 \%$ of the patients $\left(\chi^{2}=32.4, \mathrm{df}=1\right.$, corrected $\left.P<10^{-5}\right)$. Haplotypes 2 (GCGCCG) and 4 (GTGCCG) differ only in their 
Table 3 Genotype Distribution in the Study Population

Genotypic frequencies (\%)

\begin{tabular}{|c|c|c|c|c|c|c|c|c|}
\hline \multirow[b]{2}{*}{ SNP $^{\mathbf{a}}$} & \multirow[b]{2}{*}{ Polymorphism $^{b}$} & \multicolumn{3}{|c|}{ Control } & \multicolumn{3}{|c|}{ BPD } & \multirow[b]{2}{*}{$P$-value } \\
\hline & & $1-1$ & $1-2$ & $2-2$ & $I-I$ & $I-2$ & $2-2$ & \\
\hline 2 & $\mathrm{C} / \mathrm{T}$ & 33.7 & 37.8 & 28.6 & 41.1 & 44.2 & 14.7 & 0.066 \\
\hline 3 & $\mathrm{G} / \mathrm{T}$ & 3.1 & 35.7 & 61.2 & 6.3 & 41.1 & 52.6 & 0.355 \\
\hline 6 & G/A & 28.6 & 50.0 & 21.4 & 38.9 & 44.2 & 16.8 & 0.300 \\
\hline
\end{tabular}

${ }^{\mathrm{a} S N P}$ numbering as in Table I.

${ }^{\mathrm{b}}$ Allelel/allele2.

cNot corrected for multiple testing.

Table 4 D'- and P-Values for TPH-I SNP Combinations in Healthy Controls $^{\mathrm{a}}$

\begin{tabular}{lcccccc}
\hline $\mathbf{S N P}^{\mathbf{b}}$ & $\mathbf{I}$ & $\mathbf{2}$ & $\mathbf{3}$ & $\mathbf{4}$ & $\mathbf{5}$ & $\mathbf{6}$ \\
\hline $\mathrm{I}$ & & $<10^{-5}$ & $<10^{-5}$ & $<10^{-5}$ & $<10^{-5}$ & $<10^{-5}$ \\
2 & 0.467 & & $<10^{-5}$ & $<10^{-5}$ & $<10^{-5}$ & $<10^{-5}$ \\
3 & $\mathbf{0 . 7 7 1}$ & $\mathbf{0 . 7 8 5}$ & & $<10^{-5}$ & $<10^{-5}$ & 0.0008 \\
4 & 0.453 & $\mathbf{0 . 7 6 6}$ & $\mathbf{0 . 8 1 5}$ & & $<10^{-5}$ & $<10^{-5}$ \\
5 & 0.433 & $\mathbf{0 . 7 3 8}$ & $\mathbf{0 . 8 2 3}$ & $\mathbf{0 . 7 5 4}$ & & $<10^{-5}$ \\
6 & 0.462 & $\mathbf{0 . 8 2 4}$ & $\mathbf{0 . 6 6 4}$ & $\mathbf{0 . 8 6 6}$ & $\mathbf{0 . 8 1 6}$ & \\
\hline
\end{tabular}

a Upper diagonal: $P$-values for pair wise LD; lower diagonal: $D^{\prime}$-values for each SNP pair combination.

${ }^{\mathrm{b}} \mathrm{SNP}$ numbering, as listed in Table I, follows the physical location on the gene. $D^{\prime}$-values $>0.5$ are shown in bold.

Table $5 D^{\prime}$ - and P-Values for TPH-I SNP Combinations in BPD Patients $^{\mathrm{a}}$

\begin{tabular}{lcccccc}
\hline SNP $^{\mathbf{b}}$ & $\mathbf{I}$ & $\mathbf{2}$ & $\mathbf{3}$ & $\mathbf{4}$ & $\mathbf{5}$ & $\mathbf{6}$ \\
\hline $\mathrm{r}$ & & $<10^{-5}$ & $<10^{-5}$ & $<10^{-5}$ & $<10^{-5}$ & $<10^{-5}$ \\
2 & $\mathbf{0 . 6 0 6}$ & & $<10^{-5}$ & $<10^{-5}$ & $<10^{-5}$ & $<10^{-5}$ \\
3 & $\mathbf{0 . 7 7 9}$ & $\mathbf{I}$ & & $<10^{-5}$ & $<10^{-5}$ & $<10^{-5}$ \\
4 & $\mathbf{0 . 6 3 6}$ & $\mathbf{0 . 7 0 0}$ & $\mathbf{I}$ & & $<10^{-5}$ & $<10^{-5}$ \\
5 & $\mathbf{0 . 6 2 8}$ & $\mathbf{0 . 6 8 6}$ & $\mathbf{I}$ & $\mathbf{I}$ & & $<10^{-5}$ \\
6 & $\mathbf{0 . 5 6 3}$ & $\mathbf{0 . 6 4 6}$ & $\mathbf{I}$ & $\mathbf{I}$ & $\mathbf{I}$ & \\
\hline
\end{tabular}

a Upper diagonal: P-values for pair wise LD; lower diagonal: $D^{\prime}$-values for each SNP pair combination.

${ }^{\text {b}} \mathrm{SNP}$ numbering, as listed in Table I, follows the physical location on the gene. $D^{\prime}$-values $>0.5$ are shown in bold.

second SNP (rs 684302, C/T), and both maintained significance after correction for multiple testing $\left(\chi^{2}=23.1\right.$, $\mathrm{df}=1$, corrected $P<10^{-5}, \quad \chi^{2}=18.3, \quad \mathrm{df}=1$, corrected $P=0.0001$, respectively). All rare haplotypes with frequencies below $3 \%$ in both groups were pooled, since an individual haplotype analysis would have limited statistical
Table 6 Estimated Haplotype Frequencies

\begin{tabular}{llcrrr}
\hline & & \multicolumn{2}{c}{ Frequencies (\%) } & & \\
\cline { 3 - 4 } & Haplotypes $^{\mathbf{a}}$ & Control & BPD & $\chi^{\mathbf{2}}$ & $\mathbf{P}^{\mathbf{b}}$ \\
\hline 1 & A T T A A A & 26.6 & 5.0 & 32.4 & $<10^{-5}$ \\
2 & G C G C C G & 16.4 & 1.9 & 23.1 & $<10^{-5}$ \\
3 & G T T A A A & 9.4 & 28.1 & 22.5 & $<10^{-5}$ \\
4 & G T G C C G & 9.1 & 0.0 & 18.3 & 0.0001 \\
5 & G C T C C G & 8.4 & 19.9 & 10.1 & 0.0084 \\
6 & A C T C C G & 7.7 & 12.7 & 2.6 & 0.6228 \\
7 & A C G C C G & 0.0 & 24.9 & 55.2 & $<10^{-5}$ \\
8 & All rare $<3 \%$ & 22.4 & 7.4 & 17.2 & 0.0002 \\
\hline
\end{tabular}

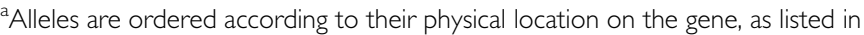
Table I.

b-value calculated for each haplotype vs all others by the $\chi^{2}$ test and corrected by Bonferroni method.

'All haplotypes with estimate frequencies $<3 \%$ in both groups.

Significant $P$-values are shown in bold.

power. This compound group was associated with the healthy control group (22.4 vs $7.4 \%$ in patients, $\chi^{2}=17.2$, $\mathrm{df}=1$, corrected $P=0.0002$ ).

A striking observation was made for haplotype 7 (Table 6, ACGCCG). This haplotype was absent in the control group, while it displayed a $24.9 \%$ frequency in the BPD group $\left(\chi^{2}=55.2, \mathrm{df}=1\right.$, corrected $\left.P \ll 10^{-5}\right)$. Except for the first SNP (rs4537731, A/G), all alleles of this haplotype are opposite to those in haplotype 1 (ATTAAA), which was associated with the control group.

\section{Three-Locus Haplotype 'Sliding Window' Analysis}

The presence of a causal polymorphism within a gene region may be reflected in a particularly strong association with disease for that region. We therefore analyzed haplotypes formed by three-locus combinations with a 'sliding window' approach, that is, SNP combinations 1-2$3,2-3-4,3-4-5$, and $4-5-6$. Table 7 shows the three-locus 
Table 7 Three-Locus Haplotype Analysis ${ }^{\mathrm{a}}$

\begin{tabular}{|c|c|c|c|c|c|}
\hline \multirow[b]{2}{*}{ Configurations $^{\mathbf{b}}$} & \multirow{2}{*}{$\begin{array}{l}\text { Three-locus } \\
\text { haplotypes }\end{array}$} & \multicolumn{2}{|c|}{ Frequencies (\%) } & \multirow[b]{2}{*}{$\chi^{2}$} & \multirow[b]{2}{*}{$P^{c}$} \\
\hline & & Control & BPD & & \\
\hline \multirow[t]{6}{*}{$1-2-3$} & ACG & 0.49 & 23.6 & 49.1 & $<10^{-5}$ \\
\hline & ATT & 33.8 & 5.8 & 47.9 & $<10^{-5}$ \\
\hline & GCG & 18.8 & 1.8 & 30.4 & $<10^{-5}$ \\
\hline & GCT & 11.5 & 23.4 & 10.4 & 0.007 \\
\hline & GTG & 9.1 & 1.0 & 13.8 & 0.001 \\
\hline & GTT & 12.1 & 29.7 & 17.8 & 0.0001 \\
\hline \multirow[t]{3}{*}{$2-3-4$} & CTC & 19.9 & 34.5 & 10.6 & 0.007 \\
\hline & TGC & 10.1 & 1.0 & 15.9 & 0.0006 \\
\hline & TTC & 6.8 & 1.0 & 8.6 & 0.020 \\
\hline \multirow[t]{2}{*}{$3-4-5$} & TCA & 4.8 & 0.0 & 10.5 & 0.007 \\
\hline & TCC & 21.7 & 35.5 & 8.9 & 0.017 \\
\hline \multirow[t]{2}{*}{$4-5-6$} & CAG & 4.1 & 0.0 & 8.3 & 0.023 \\
\hline & CCG & 46.4 & 61.0 & 8.4 & 0.022 \\
\hline
\end{tabular}

${ }^{a}$ Only haplotypes with significant associations are shown.

'Totally, four configurations are made by the six SNPs. Each configuration contains eight different combinations of three-locus haplotypes $(4 \times 8=32)$. Numbers in each configuration indicate which SNPs are included. The position of each SNP is according to their physical location on the gene, as listed in

Table I.

${ }^{c} P$-values after Bonferroni correction.

haplotypes that carried significant associations after Bonferroni correction. Most of the significant associations mapped in the configuration 1-2-3, encompassing the gene region comprised between promoter and intron 3. Haplotype combinations ACG, GCT, and GTT in this configuration were associated with the patient group (corrected $P \ll 10^{-5}, P=0.007$, and $P=0.0001$, respectively), while haplotypes ATT, GCG, and GTG were associated with the control group (corrected $P \ll 10^{-5}, P \ll 10^{-5}$, and $P=0.0012$, respectively). Configuration 2-3-4 carried three significant combinations, namely haplotype CTC was associated with BPD (corrected $P=0.007$ ), while haplotypes TGC and TTC were associated with healthy controls (corrected $P=0.0006$ and $P=0.020$, respectively). Configurations $3-4-5$ and $4-5-$ 6 each provided two significant haplotype combinations. In particular, haplotype TCC (configurations 3-4-5) was among the most frequent haplotypes $(35.5 \%$ in patients $v s$ $21.7 \%$ in controls, corrected $P=0.017$ ). The most common three-locus haplotype among those tested was CCG (configuration 4-5-6), with frequencies of $61 \%$ in patients $v s$ $46 \%$ in controls (corrected $\mathrm{P}=0.022$ ).

\section{DISCUSSION}

We have identified several $T P H-1$ gene variants associated with BPD. TPH-1 has been associated with a number of psychiatric disorders including mood disorders, violent behavior, and suicide (Mann et al, 1997; Skodol et al, 2002;
Arango et al, 2003). Most reports on TPH-1 have been association studies with individual markers (Arango et al, 2003). We are not aware of any TPH-1 association study using SNP-based haplotypes in the context of BPD.

The notion that the 5-HT system is implicated in violent and suicidal behavior is among the best established in biological psychiatry (Asberg et al, 1976; Skodol et al, 2002; Arango et al, 2003; Lieb et al, 2004). However, associating a group defined by diagnosis rather than behavior to specific biological findings has proven less amenable to experimentation (Leboyer et al, 1998). This is possibly due to a number of factors, related among others to both genotype and phenotype stratification. In the present studies, we have attempted to restrict both sources of variability, by (i) focusing on a patient group sharing ethnicity, gender, a specific DSM IV (Spitzer et al, 1992) diagnosis, and suicidal behavior; and (ii) analyzing genetic susceptibility by way of a specific gene-based haplotype analysis approach. However, as mentioned in the introduction, we have recently initiated studies aimed at applying the concept of genebased haplotype to the identification of risk haplotypes within a classical case-control study design. The six SNPs analyzed here were chosen because of a homogeneous LD pattern previously observed in a group of about 450 individuals (Gizatullin et al, 2005). In the present study, LD analysis showed that both groups share a homogeneous LD pattern with the exception of SNP 1 in the control group, which was in strong LD only with SNP 3. All other SNPs in the control group, as well as all SNPs in the BPD group were in strong LD with each other. The results support our initial observations, and suggest that all the SNPs belong to a single haplotype block. Therefore, it becomes of interest to see how such a set of SNPs behave when haplotypes are treated as risk markers.

Analyses of individual SNPs showed a marginal association with BPD for SNP 2 C allele $(P=0.035)$ with BPD (Table 2). However, no genotype association was observed, and the allele association did not maintain statistical significance after Bonferroni correction. Single marker association studies are known to be prone to generate weak associations and/or inconsistent reproducibility (Cardon and Bell, 2001; Lohmueller et al, 2003). This is due to several reasons, one of which being the fact that parent-offspring transmission of genetic variants follows certain constraints, such that most individual alleles carry only limited information on gene variants (Clark, 2004). Alleles are mostly organized in haplotype blocks, limited arrays of allelic combinations inherited with minimal recombination, and rather stably maintained in populations (Gabriel et al, 2002).

When all six SNPs were included in a haplotype analysis, almost $80 \%$ of the healthy group carried six common haplotypes, all with frequencies above 7\%. However, significant differences were observed between groups. The most striking observation was made for haplotype ACGCCG, which displayed a $25 \%$ frequency in the BPD group while being completely absent in the control group (corrected $P \ll 10^{-5}$ ). We had previously carried out the same haplotype analysis in a group of 166 major depression female outpatients with about $50 \%$ comorbidity for anxiety disorders but no history of personality disorders. In that patient group, haplotype ACGCCG was almost absent 
( $0.25 \%$ frequency, unpublished data), which suggests that the observed association is likely specific for BPD and/or suicidal behavior.

Haplotypes GTTAAA and GCTCCG were also significantly associated with BPD, each having frequencies almost three-fold higher in BPD patients than in healthy subjects. Among common haplotypes with a possible protective role, ATTAAA was carried by $26 \%$ of the controls $v s 5 \%$ in the BPD group, while GCGCCG had a frequency of about $16 \%$ in controls $v s 2 \%$ in the BPD group. It is interesting to note that the opposite haplotypes TTAAA and CGCCG (configuration 2-3-4-5-6) were associated with either group depending on SNP 1 allelic phase, that is, the presence of SNP 1 alleles A or G seemed to determine whether the resulting six-loci haplotype was associated with risk or protection. However, SNP 1 alone was not significantly associated with either group, indicating that its role is probably context-specific. In agreement with this observation, the $T P H-1$ gene region that carried the strongest association with BPD mapped in the SNP configuration 1-2-3, encompassing the gene region comprised between the promoter and intron 3. Three haplotype combinations in this configuration associated strongly with the disorder, while three more haplotypes associated strongly with the control group. The $T P H-1$ promoter region polymorphism has been analyzed in detail (Rotondo et al, 1999), and it appears to be characterized by very few haplotypes, since SNPs are almost invariably in complete LD resulting in two major haplotype blocks. The implication is that SNP 1 alleles might be considered representative of the entire promoter region sequence (approx. $2 \mathrm{~kb}$ ), suggesting that risk or protection is dependent on specific sequence combinations between promoter and primary gene transcript. Such different combinations may be reflected in the different LD values observed between SNP1 and other SNPs in controls vs patients. However, associations with BPD were also found in other configurations. Interestingly, the region mapping between introns 7 and 8 , that is, the one containing SNPs 4 and 5, which have been often reported in the literature associated with suicide and violent behavior, showed the least significant associations.

Although we report robust associations, our conclusions might be limited by several factors. First, we cannot exclude that differences in observed LD values between groups are related to population stratification. In particular, as noted in the Materials and methods, our BPD patients also had one to several diagnoses on Axis I. Also, the high LD levels observed between SNPs could be a source of redundant information in our haplotype analyses. On the other hand, it should be mentioned that the Bonferroni correction used throughout this study is very conservative, particularly in our case where measurements are not independent since the SNPs are in high LD. Finally, given the limited number of subjects analyzed in this study, our results will have to be reproduced in replica populations to be confirmed.

TPH has recently become the focus of renewed attention, as a novel isoform named TPH-2 has been discovered (Walther and Bader, 2003). While the two genes have little overall sequence homology, on the amino-acid level the proteins share about $70 \%$ identities (Walther and Bader, 2003). TPH-2 is the predominant isoform expressed in the brain stem, the major locus of 5-HT-producing neurons
(Zill et al, 2004a, b). However, TPH-1 and TPH-2 mRNA are expressed in nearly equal amounts in human brain regions such as frontal cortex, thalamus, hippocampus, hypothalamus, and amygdale (Zill et al, 2004a, b). There is extensive evidence for the presence of 5-HT nerve terminals and receptors in neuroendocrine regions such as the hippocampus and the hypothalamus (Chaouloff, 1993; Graeff, 1993). Also, 5-HT turnover is particularly active in cortical and limbic areas involved in emotional aspects of behavior (Whitaker-Azmitia et al, 1990; Westenberg, 1996). A TPH-2 haplotype analysis has recently revealed an association of the TPH-2 gene with suicidal behavior (Zill et al, 2004a). Given the close interplay between the two TPH isoforms in key brain areas related to mood and impulse control, an understanding of their relative role in pathogenic events leading to depression will require further studies on a molecular level.

The statistical significance obtained from our haplotype analysis differs greatly from that usually obtained from single locus associations including those reported here. It appears that single SNP analysis fails to capture the underlying, specific gene variant association with disease phenotype that can instead be highlighted by haplotype analysis. The potential outcome of haplotype analysis in clinical studies has been already predicted (Judson et al, 2000; Clark, 2004). In addition to an improved genotypephenotype association, our studies provide a basis for a complete molecular characterization of $\mathrm{TPH}-1$ risk variants. This in turn will facilitate the functional characterization of a gene variant's functional features, with a potentially immediate translation into disease pathogenesis studies.

\section{ACKNOWLEDGEMENTS}

For this study, financial support was received from the Swedish Science Council, and from the AFA insurance company.

\section{REFERENCES}

Abbar M, Amadeo S, Malafosse A, Shenk L, Mallet J, Castelnau D (1992). An association study between suicidal behavior and tryptophan hydroxylase marker. Clin Neuropharmacol 15: 229.

Abbar M, Courtet P, Bellivier F, Leboyer M, Boulenger JP, Castelhau D et al (2001). Suicide attempts and the tryptophan hydroxylase gene. Mol Psychiatry 6: 268-273.

Arango V, Huang YY, Underwood MD, Mann JJ (2003). Genetics of the serotonergic system in suicidal behavior. J Psychiatr Res 37: 375-386.

Asberg M, Traskman L, Thoren P (1976). 5-HIAA in the cerebrospinal fluid. A biochemical suicide predictor? Arch Gen Psychiatry 33: 1193-1197.

Brent DA, Mann JJ (2005). Family genetic studies, suicide, and suicidal behavior. Am J Med Genet C Semin Med Genet 133: 13-24.

Brown CS, Kent TA, Bryant SG, Gevedon RM, Campbell JL, Felthous AR et al (1989). Blood platelet uptake of serotonin in episodic aggression. Psychiatry Res 27: 5-12.

Cardon LR, Bell JI (2001). Association study designs for complex diseases. Nat Rev Genet 2: 91-99.

Chaouloff F (1993). Physiopharmacological interactions between stress hormones and central serotonergic systems. Brain Res Brain Res Rev 18: 1-32. 
Clark AG (2004). The role of haplotypes in candidate gene studies. Genet Epidemiol 27: 321-333.

Cloninger CR (1987). A systematic method for clinical description and classification of personality variants. A proposal. Arch Gen Psychiatry 44: 573-588.

Cochran E, Robins E, Grote S (1976). Regional serotonin levels in brain: a comparison of depressive suicides and alcoholic suicides with controls. Biol Psychiatry 11: 283-294.

Cooper JR, Melcer I (1961). The enzymic oxidation of tryptophan to 5-hydroxytryptophan in the biosynthesis of serotonin. J Pharmacol Exp Ther 132: 265-268.

Craig SP, Boularand S, Darmon MC, Mallet J, Craig IW (1991). Localization of human tryptophan hydroxylase (TPH) to chromosome $11 \mathrm{p} 15.3-\mathrm{p} 14$ by in situ hybridization. Cytogenet Cell Genet 56: 157-159.

Fu Q, Heath AC, Bucholz KK, Nelson EC, Glowinski AL, Goldberg J et al (2002). A twin study of genetic and environmental influences on suicidality in men. Psychol Med 32: 11-24.

Gabriel SB, Schaffner SF, Nguyen H, Moore JM, Roy J, Blumenstiel $B$ et al (2002). The structure of haplotype blocks in the human genome. Science 296: 2225-2229.

Gizatullin R, Zaboli G, Jonsson EG, Asberg M, Leopardi R (2005). Haplotype analysis reveals tryptophan hydroxylase (TPH) 1 gene variants associated with major depression. Biol Psychiatry, 13 September 2005 [Epub ahead of print].

Graeff FG (1993). Role of 5-HT in defensive behavior and anxiety. Rev Neurosci 4: 181-211.

Griebel G (1995). 5-Hydroxytryptamine-interacting drugs in animal models of anxiety disorders: more than 30 years of research. Pharmacol Ther 65: 319-395.

Gustavsson JP, Nothen MM, Jonsson EG, Neidt H, Forslund K, Rylander G et al (1999). No association between serotonin transporter gene polymorphisms and personality traits. Am J Med Genet 88: 430-436.

Hoehe MR (2003). Haplotypes and the systematic analysis of genetic variation in genes and genomes. Pharmacogenomics 4: 547-570.

Iny LJ, Pecknold J, Suranyi-Cadotte BE, Bernier B, Luthe L, Nair NP et al (1994). Studies of a neurochemical link between depression, anxiety, and stress from $\left[{ }^{3} \mathrm{H}\right]$ imipramine and $\left[{ }^{3} \mathrm{H}\right]$ paroxetine binding on human platelets. Biol Psychiatry 36: 281-291.

Judson R, Stephens JC, Windemuth A (2000). The predictive power of haplotypes in clinical response. Pharmacogenomics 1: 15-26.

Korpi ER, Kleinman JE, Goodman SI, Phillips I, DeLisi LE, Linnoila $\mathrm{M}$ et al (1986). Serotonin and 5-hydroxyindoleacetic acid in brains of suicide victims. Comparison in chronic schizophrenic patients with suicide as cause of death. Arch Gen Psychiatry 43: 594-600.

Kunugi H, Ishida S, Kato T, Sakai T, Tatsumi M, Hirose T et al (1999). No evidence for an association of polymorphisms of the tryptophan hydroxylase gene with affective disorders or attempted suicide among Japanese patients. Am J Psychiatry 156: 774-776.

Leboyer M, Bellivier F, Nosten-Bertrand M, Jouvent R, Pauls D, Mallet J (1998). Psychiatric genetics: search for phenotypes. Trends Neurosci 21: 102-105.

Lieb K, Zanarini MC, Schmahl C, Linehan MM, Bohus M (2004). Borderline personality disorder. Lancet 364: 453-461.

Linnoila $M$, Virkkunen $M$, Scheinin $M$, Nuutila A, Rimon R, Goodwin FK (1983). Low cerebrospinal fluid 5-hydroxyindoleacetic acid concentration differentiates impulsive from nonimpulsive violent behavior. Life Sci 33: 2609-2614.

Lohmueller KE, Pearce CL, Pike M, Lander ES, Hirschhorn JN (2003). Meta-analysis of genetic association studies supports a contribution of common variants to susceptibility to common disease. Nat Genet 33: 177-182.
Mann JJ, Malone KM, Nielsen DA, Goldman D, Erdos J, Gelernter J (1997). Possible association of a polymorphism of the tryptophan hydroxylase gene with suicidal behavior in depressed patients. Am J Psychiatry 154: 1451-1453.

Nielsen DA, Goldman D, Virkkunen M, Tokola R, Rawlings R, Linnoila M (1994). Suicidality and 5-hydroxyindoleacetic acid concentration associated with a tryptophan hydroxylase polymorphism. Arch Gen Psychiatry 51: 34-38.

Nielsen DA, Jenkins GL, Stefanisko KM, Jefferson KK, Goldman D (1997). Sequence, splice site and population frequency distribution analyses of the polymorphic human tryptophan hydroxylase intron 7. Brain Res Mol Brain Res 45: 145-148.

Nielsen DA, Virkkunen M, Lappalainen J, Eggert M, Brown GL, Long JC et al (1998). A tryptophan hydroxylase gene marker for suicidality and alcoholism. Arch Gen Psychiatry 55: 593-602.

Owens MJ, Nemeroff CB (1994). Role of serotonin in the pathophysiology of depression: focus on the serotonin transporter. Clin Chem 40: 288-295.

Rotondo A, Schuebel K, Bergen A, Aragon R, Virkkunen M, Linnoila $M$ et al (1999). Identification of four variants in the tryptophan hydroxylase promoter and association to behavior. Mol Psychiatry 4: 360-368.

Roy A, Rylander G, Sarchiapone M (1997). Genetics of suicides. Family studies and molecular genetics. Ann NY Acad Sci 836: 135-157.

Roy A, Segal NL (2001). Suicidal behavior in twins: a replication. J Affect Disord 66: 71-74.

Siever LJ, Torgersen S, Gunderson JG, Livesley WJ, Kendler KS (2002). The borderline diagnosis III: identifying endophenotypes for genetic studies. Biol Psychiatry 51: 964-968.

Silk KR, Lee S, Hill EM, Lohr NE (1995). Borderline personality disorder symptoms and severity of sexual abuse. Am J Psychiatry 152: 1059-1064.

Skodol AE, Siever LJ, Livesley WJ, Gunderson JG, Pfohl B, Widiger TA (2002). The borderline diagnosis II: biology, genetics, and clinical course. Biol Psychiatry 51: 951-963.

Soloff P, Lis JA, Kelly T, Cornelius J, Ulrich R (1994). Selfmutilation and suicidal behavior in borderline personality disorder. J Pers Disord 8: 257-267.

Soloff PH, Meltzer CC, Becker C, Greer PJ, Kelly TM, Constantine D (2003). Impulsivity and prefrontal hypometabolism in borderline personality disorder. Psychiatry Res 123: 153-163.

Spitzer RL, Williams JBW, Gibbon M, First MB (1990). Structured Clinical Interview for DSM-III-R, Patient Edition/Non-patient Edition, (SCID-P/SCID-NP). American Psychiatric Press, Inc.: Washington, DC.

Spitzer RL, Williams JB, Gibbon M, First MB (1992). The Structured Clinical Interview for DSM-III-R (SCID). I: History, rationale, and description. Arch Gen Psychiatry 49: 624-629.

Statham DJ, Heath AC, Madden PA, Bucholz KK, Bierut L, Dinwiddie SH et al (1998). Suicidal behaviour: an epidemiological and genetic study. Psychol Med 28: 839-855.

Swartz M, Blazer D, George L, Winfield I (1990). Estimating the prevalence of borderline personality disorder in the community. J Pers Disord 4: 257-272.

Torgersen S (1984). Genetic and nosological aspects of schizotypal and borderline personality disorders. A twin study. Arch Gen Psychiatry 41: 546-554.

Torgersen S (1987). Sampling problems in twin research. J Psychiatr Res 21: 385-390.

Torgersen S, Lygren S, Oien PA, Skre I, Onstad S, Edvardsen J et al (2000). A twin study of personality disorders. Compr Psychiatry 41: 416-425.

Tsai SJ, Hong CJ, Wang YC (1999). Tryptophan hydroxylase gene polymorphism (A218C) and suicidal behaviors. NeuroReport 10: $3773-3775$. 
Walther DJ, Bader M (2003). A unique central tryptophan hydroxylase isoform. Biochem Pharmacol 66: 1673-1680.

Westenberg HG (1996). Developments in the drug treatment of panic disorder: what is the place of the selective serotonin reuptake inhibitors? J Affect Disord 40: 85-93.

Whitaker-Azmitia PM, Shemer AV, Caruso J, Molino L, Azmitia EC (1990). Role of high affinity serotonin receptors in neuronal growth. Ann NY Acad Sci 600: 315-330.

Zanarini MC, Yong L, Frankenburg FR, Hennen J, Reich DB, Marino MF et al (2002). Severity of reported childhood sexual abuse and its relationship to severity of borderline psychopathology and psychosocial impairment among borderline inpatients. J Nerv Ment Dis 190: 381-387.

Zill P, Baghai TC, Zwanzger P, Schule C, Eser D, Rupprecht R et al (2004a). SNP and haplotype analysis of a novel tryptophan hydroxylase isoform (TPH2) gene provide evidence for association with major depression. Mol Psychiatry 9: 1030-1036.

Zill P, Buttner A, Eisenmenger W, Bondy B, Ackenheil M (2004b). Regional mRNA expression of a second tryptophan hydroxylase isoform in postmortem tissue samples of two human brains. Eur Neuropsychopharmacol 14: 282-284. 